Title: Low omega-3 fatty acid levels associate with frequent gout attacks - a case control study

Authors: A Abhishek ${ }^{1}$, Ana M Valdes ${ }^{1}$, Michael Doherty ${ }^{1}$

Affiliation: Academic Rheumatology, University of Nottingham, Clinical Sciences

Building, Nottingham City Hospital, Nottingham NG5 1PB, UK

Address for correspondence:

Dr. A. Abhishek, PhD

Academic Rheumatology

University of Nottingham

Nottingham NG5 1PB

United Kingdom

Phone: +441158231392

Fax: +441158231757

Email: Abhishek.abhishek@nottingham.ac.uk

Word count: 500

Keywords: Gout, acute gout, omega-3 fatty acids, 
Eicosapentaenoic acid and docosahexaenoic acid are omega-3 polyunsaturated fatty acids with anti-inflammatory effects. They inhibit several pathways like toll like receptor activation, NALP-3 inflammasome assembly, neutrophil chemotaxis, prostaglandin synthesis and nucleating factor-kB activity through which monosodium urate (MSU) crystals induce inflammation (1-6). In keeping with these findings, mice fed on diet rich in omega-3 fatty acids developed less inflammation after subcutaneous injection of MSU crystals than those on standard diets $(1,7)$. Thus, omega- 3 fatty acids have the potential of preventing acute attacks of gout. However, the association between omega-3 fatty acid levels and frequency of gout attacks has not been examined in humans. The objective of this study was to examine if omega- 3 fatty acid levels associate with frequent gout attacks.

This study was approved by the Nottinghamshire Research Ethics Committee-1. Data from 112 men with gout meeting the American College of Rheumatology classification criteria for gout and recruited from primary care were used (8). Patients were seen for one visit, had detailed metrologist assessments including height and weight measurement, self-reported their gout attack frequency in the previous 12 months, and had blood taken for measurement of omega-3 fatty acid and serum uric acid (SUA). For the present study, cases had $>2$ acute attacks while controls had $\leq 2$ acute attacks of gout in the preceding 12 months. Odds ratio (OR) and 95\% confidence intervals $(95 \% \mathrm{Cl})$ were calculated to examine the association between omega-3 fatty acid levels and gout attack frequency. This was adjusted for age, body mass index $\left(\mathrm{kg} / \mathrm{m}^{2}\right)$, disease duration and SUA (tertiles); and tophi, urate lowering treatment (absent or present) using binary logistic regression. Statistical analyses were carried out using Stata. Statistical significance was $p<0.05$. 
The characteristics of the study participants are described in Table 1. The mean (SD) omega-3 fatty acid level was $0.41(0.11) \mathrm{mmol} / \mathrm{L}$. There was a non-significant trend for a negative association between omega- 3 fatty acid levels and $>2$ acute attacks of gout in the previous 12 months $(\mathrm{OR}(95 \% \mathrm{Cl}) 0.68(0.46-1.02)$ ptrend 0.06$)$, however, it became significant after adjusting for covariates $\left(\mathrm{aOR}(95 \% \mathrm{Cl}) 0.62(0.38-0.98), p_{\text {trend }}\right.$ 0.043) (Figure 1).

This is the first report of an association between high omega-3 fatty acid levels and infrequent acute attacks of gout. This novel finding raises the possibility that supplementation with omega-3 fatty acids may be used to prevent acute attacks of gout. However, there are several caveats to the study. Firstly, the frequency of gout attack was self-reported retrospectively, and may be affected by biased recall. However, self-reported gout attack frequency is unlikely to be affected by the omega3 fatty acids levels, and will not result in a differential misclassification bias. Additionally, information about other factors that may affect gout attack frequency e.g. purine-rich alcohol consumption, red meat intake, and both gout attack frequency and omega-3 fatty acid levels e.g. sea-food intake were not available. Thus, the findings of this study should be confirmed in other studies in which information on lifestyle and dietary risk factors that affect gout attack frequency are collected. 
Competing Interests None declared

Contributorship $\mathrm{AA}, \mathrm{AV}$ and $\mathrm{MD}$ conceived the study. AA performed the data analysis. AA, AV and MD critically appraised the manuscript and approved the final version

\section{Acknowledgements None}

Funding info No specific funding was obtained for this study

Ethical approval information Approved by the Nottinghamshire Research Ethics Committee-1

Data sharing statement Data used in this study are held in Academic Rheumatology, University of Nottingham, UK, under the custody of Prof. Michael Doherty and can be made available on request. 
Table 1 Disease and demographic characteristics of the study participants

\begin{tabular}{|c|c|c|c|}
\hline & $\begin{array}{c}\text { Cases } \\
(n=31)\end{array}$ & $\begin{array}{c}\text { Controls } \\
(n=81)\end{array}$ & $\begin{array}{c}p \\
\text { value }\end{array}$ \\
\hline Age, mean $\left(S^{1}{ }^{1}\right)$ & $59.67(11.45)$ & $64.44(10.22)$ & 0.03 \\
\hline BMI, mean (SD) & $29.54(5.32)$ & $29.86(4.57)$ & 0.76 \\
\hline Disease duration, mean (SD) & $9.53(7.52)$ & $12.93(10.89)$ & 0.11 \\
\hline Tophi, n (\%) present & $4(12.9 \%)$ & $4(5.0 \%)$ & 0.14 \\
\hline Serum uric acid, mean (SD) & $424.52(112.70)$ & $391.77(98.33)$ & 0.13 \\
\hline $\mathrm{n}(\%)$ on urate lowering treatment & $11(35.5 \%)$ & $36(44.44 \%)$ & 0.74 \\
\hline \multicolumn{4}{|l|}{ Omega-3 fatty acid, range (mmol/L) } \\
\hline$\leq 0.355$ & 9 & 18 & \\
\hline $0.361-0.4025$ & 10 & 16 & \\
\hline $0.4067-0.4648$ & 5 & 21 & \\
\hline$\geq 0.4659$ & 4 & 22 & $0.06^{2}$ \\
\hline
\end{tabular}

${ }^{1} \mathrm{SD}$ (Standard Deviation); ${ }^{2} \mathrm{p}_{\text {trend }}$ 
Figure 1 Negative association between frequent gout attacks and increasing concentration of omega 3 fatty acid. The OR for frequent gout attack reduces with increasing concentration of omega 3 fatty acid.

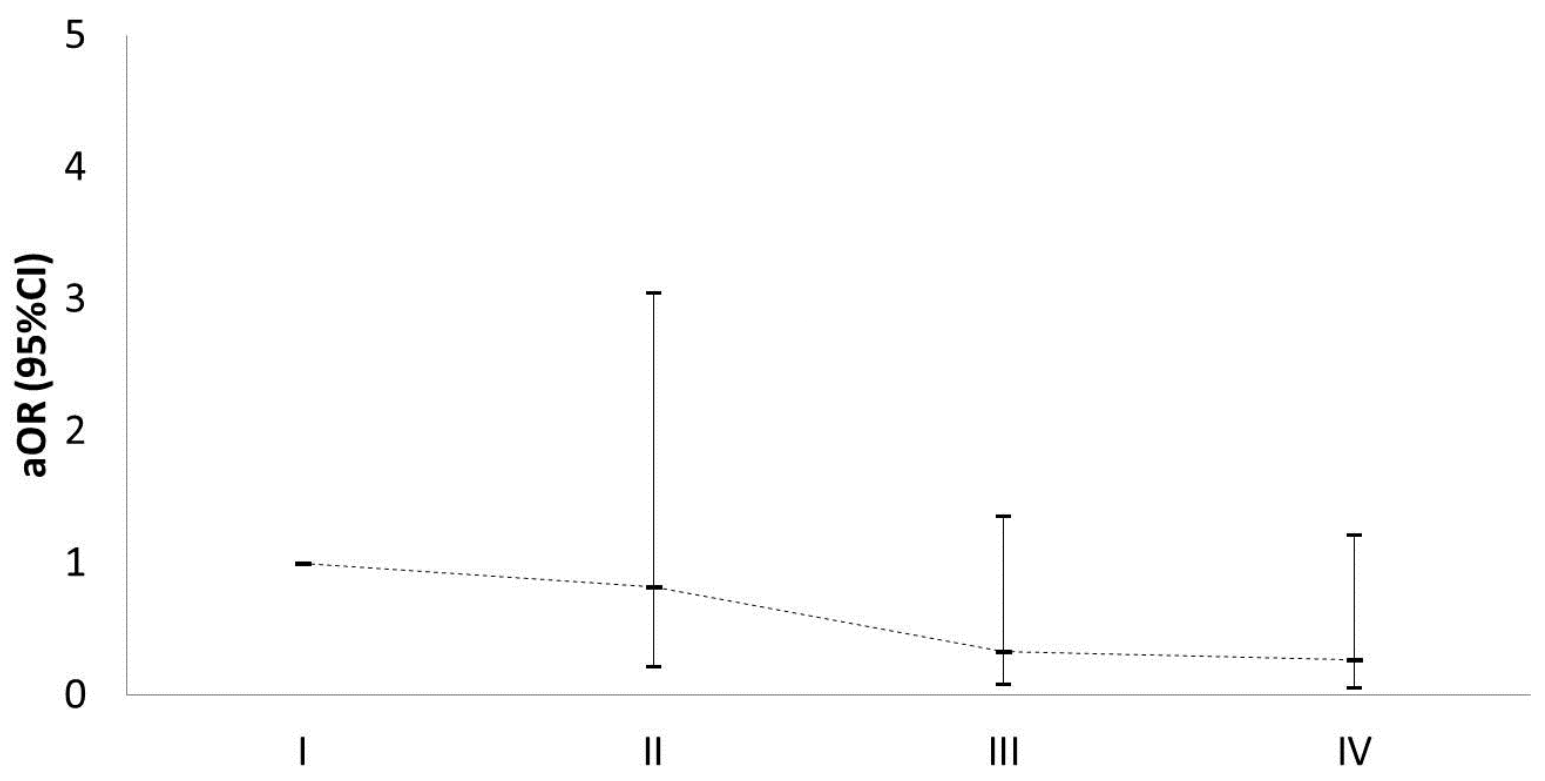

Quartiles of omega-3 fatty acid concentration

6 


\section{References:}

1. Tate GA, Mandell BF, Karmali RA, Laposata M, Baker DG, Schumacher HR, Jr., et al. Suppression of monosodium urate crystal-induced acute inflammation by diets enriched with gamma-linolenic acid and eicosapentaenoic acid. Arthritis Rheum. $1988 ; 31(12): 1543-51$.

2. Yan Y, Jiang W, Spinetti T, Tardivel A, Castillo R, Bourquin C, et al. Omega-3 fatty acids prevent inflammation and metabolic disorder through inhibition of NLRP3 inflammasome activation. Immunity. 2013;38(6):1154-63.

3. Snodgrass RG, Huang S, Choi IW, Rutledge JC, Hwang DH. Inflammasomemediated secretion of IL-1beta in human monocytes through TLR2 activation; modulation by dietary fatty acids. Journal of immunology (Baltimore, Md : 1950). 2013;191(8):4337-47.

4. Oh DY, Talukdar S, Bae EJ, Imamura T, Morinaga H, Fan W, et al. GPR120 is an omega-3 fatty acid receptor mediating potent anti-inflammatory and insulinsensitizing effects. Cell. 2010;142(5):687-98.

5. Schmidt EB, Pedersen JO, Varming K, Ernst E, Jersild C, Grunnet N, et al. n-3 fatty acids and leukocyte chemotaxis. Effects in hyperlipidemia and dose-response studies in healthy men. Arteriosclerosis and thrombosis : a journal of vascular biology I American Heart Association. 1991;11(2):429-35.

6. Calder PC. Omega-3 polyunsaturated fatty acids and inflammatory processes: nutrition or pharmacology? British journal of clinical pharmacology. 2013;75(3):64562.

7. Tate G, Mandell BF, Laposata M, Ohliger D, Baker DG, Schumacher HR, et al. Suppression of acute and chronic inflammation by dietary gamma linolenic acid. $\mathrm{J}$ Rheumatol. 1989;16(6):729-34. 
8. Wallace SL, Robinson H, Masi AT, Decker JL, McCarty DJ, Yu TF. Preliminary criteria for the classification of the acute arthritis of primary gout. Arthritis and rheumatism. 1977;20(3):895-900. 